\title{
Giant staghorn common bile duct calculus
}

\author{
Ranendra Hajong • Noor Topno • Arup J Baruah • \\ Donkupar Khongwar
}

Published online: 29 April 2012

(C) Indian Society of Gastroenterology 2012

Staghorn calculus in the common bile duct (CBD) is rare. Few reports have described a giant stone measuring $5 \mathrm{~cm}$ or more in the CBD [1]. We could find only one published report of staghorn common bile duct calculus [2].

A 48-year-old lady presented with chronic pain upper abdomen and mild icterus. Ultrasonography followed by magnetic resonance cholangiopancreaticography (MRCP)

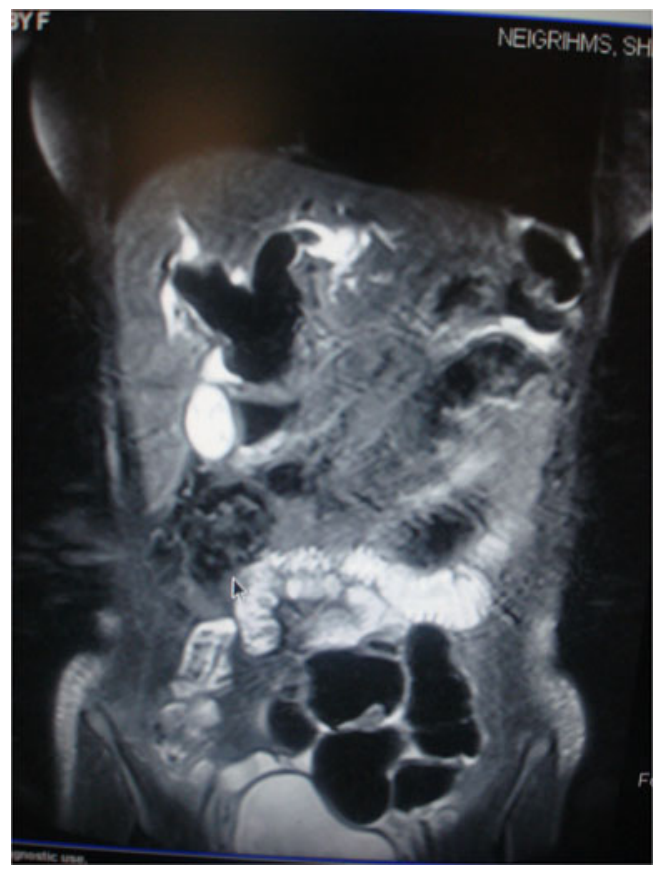

Fig. 1 MRI showing staghorn common bile duct calculus

\footnotetext{
R. Hajong $(\bowtie) \cdot$ N. Topno $\cdot$ A. J. Baruah $\cdot$ D. Khongwar

Department of Surgery, NEIGRIHMS,

Shillong, Meghalaya 793 018, India

e-mail: ranenhajong@gmail.com
}

showed dilated CBD impacted with stones (Fig. 1). The patient underwent open cholecystectomy and CBD exploration. At surgery, the stone was tightly impacted in the CBD and extended into both hepatic ducts, measuring approximately $8 \mathrm{~cm} \times 6 \mathrm{~cm}$ (Fig. 2). The stone was extracted with difficulty and hepaticojejunostomy was done. The patient recovered uneventfully and was discharged from the hospital on 10th postoperative day.



Fig. 2 Image of staghorn common bile duct calculus

\section{References}

1. Bahuleyan CK. Giant common bile duct calculus. Indian J Surg. 1975;37:82.

2. Jayant M, Dalal AK, Attri AK, Sachdev A. Giant staghorn stone in common bile duct. Indian J Gastroenterol. 2010;29:212. 